\title{
POSSIBILIDADES FUTURAS NA TERAPÊUTICA DE DIVERSAS PATOLOGIAS UTILIZANDO COMPOSTOS CANABINÓIDES
}

\author{
Natália Cruz Oliveira ${ }^{1}$ \\ Rafael Mariano de Bitencourt ${ }^{2}$
}

RESUMO: A Cannabis é uma planta conhecida há milênios por suas propriedades medicinais. Segundo estudos, a Cannabis possui compostos canabinóides capazes de auxiliar na terapia do controle da dor, transtornos psiquiátricos, epilepsia, entre outros. Os estudos feitos com os compostos da Cannabis têm proporcionado aos pesquisadores descobertas de receptores no organismo que eram desconhecidos até então. Mesmo sendo considerada ainda como uma droga recreativa, a Cannabis e seus compostos já vêm sendo utilizados em medicamentos em alguns lugares do mundo, provando ser passível de comercialização, e sua legalização está ocorrendo em diversos países. O presente trabalho faz uma revisão sobre a possível utilização terapêutica dos canabinóides em diferentes patologias.

Palavras-chave: Cannabis. Canabinóides. Possibilidades Terapêuticas.

ABSTRACT: Cannabis is a plant known for millennia for its medicinal properties. According to studies the Cannabis plants has cannabinoid compound capable of assisting in pain control therapy, psychiatric disorders, epilepsy, among others. Studies performed with the compounds of Cannabis has provided the researchers with findings of receptors in the body that were unknown until then. Even though it is still regarded as a recreational drug, the Cannabis plant and its compounds are already used in medications in some parts of the world, proving its capability of being commercialized, and its legalization is occurring in many countries. This paper reviews the possible therapeutic use of cannabinoids in different pathologies.

Keywords: Cannabis. Cannabinoids. Therapeutic Possibilities.

\footnotetext{
I Graduação em Farmácia pela Universidade do Oeste de Santa Catarina(2016). Tem experiência na área de Farmácia, com ênfase em Farmácia clínica, assistência e atenção farmacêuticas.

${ }^{2}$ Possui graduação em Farmácia pela Universidade do Extremo Sul Catarinense - UNESC (2004), Mestrado (2008) e Doutorado (2012) em Farmacologia pela Universidade Federal de Santa Catarina - UFSC. Durante o doutorado, passou um período de seis meses no Centro de Neurociências da Universidade de Coimbra, em Portugal, para a realização de Doutorado Sanduíche. Seus estudos estão voltados para a compreensão do sistema endocanabinóide, bem como as possibilidades terapêuticas acerca deste sistema. Atualmente é professor titular do Programa de Pós-graduação em Ciências da Saúde (PPGCS), onde coordena o Laboratório de Neurociência Comportamental (LabNeC), e professor do curso de Psicologia, ambos na Universidade do Sul de Santa Catarina - UNISUL. Professor do curso de Pós-Graduação, nível Especialização em Farmacologia, da Universidade do Extremo Sul Catarinense - UNESC. Professor nas Faculdades Esucri - Escola Superior de Criciúma e no Centro Universitário UNIFACVEST em Lages-SC.

-Autor correspondente: Rafael Mariano de Bitencourt, Professor doutor em Farmacologia na Universidade do Oeste de Santa Catarina - UNOESC, Campus Videira; Rua Paese, 198, Bairro Universitário, Videira, SC, 8956o-ooo. Email: bitencourtrm@gmail.com.
} 


\section{INTRODUÇÃO}

A Cannabis é conhecida há milênios por suas propriedades analgésicas, antieméticas e tranquilizantes. Os chineses foram os primeiros a relatar o uso medicinal da planta há 2000 anos, quando a atribuíram à Farmacopéia Chinesa (Zuardi, 2006-A). Foi relatado que o imperador ShenNung prescrevia a planta no tratamento de beribéri, fadiga, gota, constipação entre outros. Já os assírios, há 300 anos, utilizavam a planta como composto principal em sua farmacopéia, dizendo que era a "droga que extraia a mente" (Honório, Arroio e silva, 2006 apoud Mechoulam, 1999).

Em 1839, o médico irlandês Dr. Willian B. O’Shaugnessy e o psiquiatra francês JacquesJoseph Moreau, relataram que na Índia a Cannabis era utilizada em tratamentos antiespasmódicos, anti-convulsionantes, contra o tétano e hidrofobia. O primeiro artigo científico da planta surgiu em quatro de fevereiro de 1843, escrito pelo Dr. O'Shaugnessy, sob o título de “On the Preparations of Indian Hemp, or Gunjah, (Cannabis indica)", no qual indicava que o extrato da planta era rico em canabinóides terapêuticos. Então, em 1844, a tintura da Cannabis foi introduzida na Europa e na América do Norte fazendo parte de suas respectivas farmacopéias, passando assim a ser disseminada na medicina ocidental e utilizada como medicação sedativa, hipnótica e anticonvulsivante (MalcherLopes e Ribeiro, 2007).

No final do século XIX, a Cannabis foi considerada por grandes indústrias farmacêuticas como uma droga promissora e passível de comercialização. No início do século XX, vários laboratórios farmacêuticos produziam medicamentos à base de Cannabis, incluindo os gigantes Merck (Alemanha), Bristol-Meyers Squibb (Estados Unidos) e Eli-Lilly (Estados Unidos) (Kalant, 2001). Na década de 1960, o consumo recreativo da Cannabis aumentou, sendo utilizada como maneira de protesto e descontentamento acerca do governo capitalista da Europa e América do Norte, e sua utilização para o uso medicinal foi entrando em declínio, sendo substituída por drogas com efeitos mais previsíveis (Bonfá et al., 2008).

Nos dias atuais, a planta é vista com um vasto potencial terapêutico, sendo estudada por pesquisadores de vários lugares do mundo. Em certos países ou estados, a droga já foi legalizada, tanto para sua utilização terapêutica como para seu consumo recreativo. Podemos citar como exemplo Holanda e Bélgica, que liberaram o uso da Cannabis para aliviar sintomas relacionados ao tratamento de câncer, AIDS, esclerose múltipla e síndrome de Tourette (Bonfá et al., 2008 apoud Robson, 200I). 
O Brasil, pátria de alguns pesquisadores de relevância mundial na pesquisa em canabinóides, está recentemente entrando nesta discussão, com a autorização da Agência Nacional de Vigilância Sanitária (ANVISA) para a importação dos extratos padronizados produzidos por indústrias farmacêuticas internacionais destinadas a tratar de casos graves de epilepsia, refratários aos tratamentos tradicionais (ANVISA, 2014). Reconhece-se que os extratos padronizados com alto teor de canabidiol (CBD) conseguem reduzir drasticamente a frequência e a severidade das convulsões, sendo utilizado inclusive em pacientes infantis (Pamplona, 20I4 apoud Hughes, 2013).

Por ser considerada uma droga ilícita, o uso terapêutico da Cannabis não é bem elucidado. Seus potenciais terapêuticos, efeitos adversos e mecanismos de ação continuam sendo um grande enigma para muitos pesquisadores. Busca-se ainda saber se está planta e seus compostos poderão ser utilizados como terapia medicamentosa. Sendo assim, o presente trabalho pretende fazer uma revisão acerca dos componentes da Cannabis bem como seu possível potencial terapêutico.

\section{METODOLOGIA}

O presente trabalho trata-se de uma pesquisa bibliográfica sobre os canabinóides e suas possibilidades terapêuticas. A pesquisa foi feita de modo qualitativo, não utilizando corte cronológico. Foram utilizados como meios de pesquisa: livros didáticos, base de dados Scielo, Lilacs, Pubmed.

\section{REVISÃO DA LITERATURA}

\section{Cannabis sativa, compostos e receptores}

A Cannabis sativa é uma planta anual e dióica, de caules eretos e ramificados na base, cujas folhas pecioladas têm segmentos lanceolados serrados na margem. As plantas masculinas diferem das femininas por possuírem um porte maior, ramos mais finos e folhas mais longamente lanceoladas. Sua altura pode variar de um a cinco metros quando cultivada em condições favoráveis, e geralmente morrem após polinizar a feminina. Por outro lado, as plantas fêmeas são menores, e suas flores aparecem resumidas em espigas de glomérulos contraídas, porém, nelas encontra-se a maior porcentagem de compostos psicoativos (entre io a 20\%) (Costa, 1970). Este tipo de Cannabis se difere da C. indica, pois possui efeitos mais eufóricos do que sedativos. Suas fibras são utilizadas na produção têxtil e seu óleo em pinturas (Honório, Arroio e Silva, 2006). 
Há cerca de 6o componentes químicos conhecidos na planta, denominados canabinóides. Podemos destacar, entre eles, o $\Delta 9$-THC (delta-9-tetrahidrocanabinol) e o Canabidiol, que agem em todo o organismo e no sistema nervoso central (SNC) (Honório, Arroio e Silva, 2006; Petrocellis, Cascio e Marzo, 2004). Os tipos de canabinóides podem ser classificados de duas maneiras: psicoativos ou não psicoativos. O THC é classificado como psicoativo, assim como seus derivados, enquanto que o Canabidiol é considerado não psicoativo (Honório, Arroio e Silva 2006).

Por volta dos anos 8o, foi descoberto que os canabinóides atuam ao se ligarem em receptores endógenos (Honório, Arroio e Silva 2006 apoud Howlet, 1984). Até agora, pôde-se concluir que há dois tipos de receptores endógenos: o $\mathrm{CB}_{1}$ e o $\mathrm{CB} 2$. A descoberta destes receptores deve-se ao fato de que Howlet, ao isolar o composto THC, notou que este inibia a enzima intracelular adenilato ciclase e que tal inibição só ocorria na presença de um complexo de proteínas-G, ou seja, na presença de um receptor canabinóide, o qual é um membro típico da maior família conhecida de receptores: receptores acoplados às proteínas-G (Matsuda et al., 1990).

No organismo, os canabinóides se ligam a receptores específicos, como o CBr e O CB2. Os receptores $\mathrm{CB}_{\mathrm{I}}$ encontram-se no sistema nervoso central, estando presentes em áreas mediadoras das funções cognitivas, coordenação motora, dor, memória em curto prazo, hipotermia, hiperfagia. Sendo encontrados também na medula espinhal, gânglios da medula dorsal, sistema nervoso entérico, adipócitos, células endoteliais, entre outros. Os receptores $\mathrm{CB}_{2}$ estão localizados em sua grande maioria no sistema nervoso periférico, e se relacionam com o sistema imune (Francischetti e Abreu, 2006 apoud Munro et al., 1993).

Tendo conhecimento sobre os receptores canabinóides, buscou-se descobrir se haveria ligantes endógenos para estes receptores. Uma das substâncias encontradas foi chamada de Anandamida (N-aracdonil-etanolamina), uma substância muito semelhante ao THC. A anandamida tem a capacidade de se ligar ao receptor CBI, e é metabolizada pelas amilases, constituída de ácido araquidônico e etanolamina. Este endocanabóide, como é chamado, é encontrado em porções do cérebro como hipocampo e cerebelo, possuindo um curto período de ação e as mesmas propriedades farmacológicas do THC (Honório, Arroio e Silva, 2006).

Tendo descoberto os receptores canabinóides e seus ligantes endógenos, as pesquisas foram direcionadas no sentido de esclarecer quais as funções deste sistema endocanabinóide, no funcionamento do nosso organismo. Algumas hipóteses revelam que o sistema endocanabinóide 
tem envolvimento nos processos de antinociceptividade, (diminuindo a sensação de estímulos dolorosos), atua na diminuição de secreção de prolactina e hormônio adrenocorticotrófico, tem participação nas respostas de ansiedade e sobre o humor, auxilia na modulação da resposta imune e na ingestão de alimentos, além de aumentar a frequência cardíaca, e ter participação na broncodilatação e vasodilatação (Francischetti, 2006).

\section{Canabinóides para o tratamento da dor}

A dor pode ser vista como uma sensação desagradável contraída por fatores emocionais, ambientais e lesões teciduais, podendo também ter características crônicas, onde a dor persiste por tempo maior do que o necessário para a cura de uma lesão (Dellaroza, Pimenta e Matsuo, 2008).

Como se sabe, a primeira escolha de tratamento para dor são os anti-inflamatórios não esteroidais (AINES), porém, se houver persistência da dor, estes devem ser substituídos por opióides fracos que, por sua vez, podem ser substituídos por opióides fortes. Uma vez que opióides fortes podem causar muitas modificações no organismo e levar à dependência, os canabinóides têm sido vistos como uma nova esperança terapêutica para a dor. Os canabinóides podem auxiliar os opióides fracos no tratamento da dor, sem induzir dependência ou síndrome de abstinência (Cruz e Gonçalves, 2014 apoud Torres, Trinidad e Calderon, 2013).

Em 2006, o uso da Cannabis e seus componentes começaram a ter sua eficácia terapêutica comprovada cientificamente. Trabalhos mostraram que a administração de THC e Canabidiol era capaz de induzir analgesia (Zuardi, 2006-A). Em busca de conhecer melhor as propriedades analgésicas dos canabinóides, pesquisadores demonstraram, através de estudos, que há um aumento dos receptores CBI quando ocorre uma dor, explicando, em parte, o porquê dos efeitos analgésicos destes compostos. Há relatos de que os canabinóides, juntamente com a morfina, proporcionam um tratamento eficaz da dor sem causar uma depressão respiratória (Honório, Arroio e Silva, 2006).

Por estarem presentes em áreas moduladoras da dor no sistema nervoso central e periférico, os interesses em utilizar os canabinóides como alvo terapêutico tem sido motivo de muitos estudos por parte dos pesquisadores, uma vez que este alvo pode ser útil no controle da dor crônica, pósoperatória ou aguda, além da dor oriunda do câncer e outras formas de dor (Campbell, 20or). Segundo Campbell et al., os canabinóides devem ser utilizados como terapia adjunta no 
tratamento da dor, uma vez que estes, em dosagem única, não produzem os mesmos efeitos analgésico de alta potência observados com a administração de codeína. Contudo, os canabinóides, em conjunto com os opióides, podem aumentar a eficiência do tratamento, sem que para isso seja necessário utilizar excesso de analgésicos opióides fortes (Campbell, 200I).

\section{Canabinóides e transtornos psiquiátricos}

Nos últimos anos, houve um número crescente de publicações científicas a respeito dos canabidióis como ansiolíticos (Zuardi, 2006-B). Em dois estudos, observou-se certa contradição acerca de seus efeitos terapêuticos. Um estudo feito em roedores demonstrou que, em doses maiores que 1oo $\mathrm{mg} / \mathrm{kg}$, o canabidiol não possui efeito ansiolítico. Neste estudo foram utilizados o teste de conflito e o da ingestão de alimentos suprimida pela neofobia (Silveira e Tufik, 198I). Já em outro estudo, Zuardi e Karniol, no ano de 1983, demonstraram que em doses usuais de $10 \mathrm{mg} / \mathrm{kg}$ houve uma diminuição da resposta emocional condicionada e o $\Delta 9-\mathrm{THC}(2 \mathrm{mg} / \mathrm{kg})$ aumentou esta resposta (Zuardi e Karniol, 1983).

Após estes testes, outros estudos acerca da hipótese do canabidiol ter efeito ansiolítico, foram feitos com animais, como: testes de conflito (comportamento de beber, suprimido por choque elétrico concomitante) em ratos privados de água (Musty; Conti; Mechoulam 1984), respostas comportamentais e cardiovasculares dos roedores no paradigma de medo condicionado (choque nas patas) (Restel, 2006), teste do estresse por imobilização (Restel, 2009), extinção de memória de medo condicionado (Bitencourt, 2008), labirinto em cruz elevada em camundongos (Onaivi, 1990) e ratos (Campos e Guimarães, 2009). Todos esses testes confirmaram o potencial ansiolítico do canabidiol, e uma hipótese para explicar estes efeitos é de que o canabidiol estaria atuando através da interação dos receptores ${ }_{5} \mathrm{HT}_{\mathrm{I}} \mathrm{A}$ ou então potencializando a ação endocanabinóide (Crippa; Zuardi; Hallak, 20ı; Bitencourt et al. 2008).

Um teste com voluntários saudáveis que apresentavam problemas de oratória foi feito da seguinte maneira: os voluntários ficavam em frente a uma câmera de vídeo e falavam durantes alguns minutos, então sua ansiedade subjetiva era registrada por meio de escalas de auto avaliação, bem como seu estado fisiológico (pressão arterial e frequência cardíaca). Comparou-se os resultados produzidos pelos voluntários que estavam sobre efeito de canabidiol (300 $\mathrm{mg}$ ) com os voluntários que estavam sobre efeito placebo e por dois ansiolíticos (diazepam ı mg, ipsapirona 
5mg). Os resultados mostraram que tanto o canabidiol como os dois ansiolíticos atenuaram a ansiedade dos participantes (Crippa; Zuardi; Hallak, 2010).

Um conjunto de resultados de testes avaliando o canabidiol e os efeitos modulatórios deste composto na ativação de áreas límbicas e paralímbicas demonstrou que o canabidiol tem efeito consistente em pacientes com transtornos psiquiátricos (Crippa; Zuardi; Hallak, 20Io). Por exemplo, em um estudo comparando o canabidiol com o haloperidol na ação antipsicótica em roedores, pôde-se observar que ambos diminuíram de forma dose-dependente comportamentos como morder e cheirar repetidamente. Sendo que no teste de catalepsia (tempo de permanência com as patas dianteiras apoiadas numa barra elevada) o canabidiol não apresentou resultados, enquanto o haloperidol sim (Zuardi, Rodrigues e Cunha, 199I).

Ao estudar os efeitos do canabidiol na hiperlocomoção induzida por anfetamina e ketamina em camundongos, notou-se que o canabidiol inibia a hiperlocomoção (Moreira e Guimarães, 2005). Em humanos, a utilização de modelos experimentais de psicopatologias fornece indicações importantes sobre os efeitos terapêuticos das drogas, precedendo os ensaios clínicos com pacientes. Baseados nesta afirmação, um dos modelos mais utilizados para avaliação de um possível efeito antipsicótico do canabidiol é o da inversão de percepção binocular, resultando em uma diminuição de imagens ilusórias produzidos pela nabilona (canabinóide sintético), sugerindo efeito semelhante aos antipsicóticos utilizados por pacientes com esquizofrenia (Leweke et al.,200o).

Com bases em estudos sobre o efeito antipsicótico do canabidiol, e evidências de uma possível disfunção do sistema endocanabinoide na esquizofrenia, Crippa, Zuardi e Hallack investigaram os efeitos deste composto na atenção seletiva e no padrão de resposta eletrodérmica a estímulos auditivos em pacientes com este transtorno. $O$ teste consistiu em submeter vinte e oito pacientes avaliados em duas sessões por meio do Stroop Color Word Test (teste de conflito de cognição), sendo que em uma das sessões não houve administração de drogas e, na segunda, houve uma divisão em três grupos. Os pacientes receberam dose única de canabidiol na seguinte dosagem: grupo I (300 mg), grupo 2 (6oomg) e grupo 3 (placebo). Os resultados foram de que o canabidiol utilizado em dose única não demonstrou efeito sobre os pacientes, não descartando a hipótese de que, em administração crônica, o canabidiol possa melhorar o funcionamento cognitivo em pacientes com esquizofrenia (Crippa; Zuardi; Hallak, 20Io).

Modelos de teste que utilizam a ketamina para indução de estados psicóticos em sujeitos saudáveis sugerem que o canabidiol, se comparado a um placebo, pode atenuar os efeitos 
dissociativos produzidos pela ketamina. Este resultado reforça a hipótese de um possível efeito terapêutico do canabidiol em transtornos de personalidade (Crippa; Zuardi; Hallak, 201o).

Sintomas psicóticos podem ser comuns em pacientes com doença de Parkinson, sendo um grande desafio para os clínicos (Naimarket al., 1996). Isto ocorre por vários fatores: redução de doses dos antiparkisonianos que levam a uma piora nos sintomas motores, uso de antipsicóticos convencionais que levam uma piora no quadro motor e utilização da clozapina (antipsicótico atípico), que causa efeitos colaterais relevantes (Thanvi, 2005). Com base nestes dados, Zuardi e outros pesquisadores avaliaram a eficácia, segurança e tolerabilidade do canabidiol em pacientes com doença de Parkinson e psicose. Os pacientes foram submetidos à administração de canabidiol em uma dose oral de $150 \mathrm{mg} /$ dia por quatro semanas, além de suas terapias usuais. Notou-se que os sintomas psicóticos e motores reduziram e não houve piora nos sintomas cognitivos, sugerindo que o canabidiol pode ter um efeito na doença de Parkinson (Zuardi et al., 2008).

O canabidiol teve como um dos seus primeiros efeitos observados a sedação, baseada na observação de que este canabinóide reduzia a ambulação e comportamento operante em ratos (Karniol e Carlini, 1973). Em um estudo feito com humanos voluntários que sofriam de insônia, o canabidiol demonstrou que este pode induzir uma melhora de sono nos voluntários (Carlini e Cunha, 198I).

Com base na hipótese de que os possíveis efeitos ansiolíticos do canabidiol estejam relacionados aos receptores serotoninérgicos, e que esta relação possa induzir efeitos antidepressivos, avaliou-se, por meio do modelo de nado forçado de camundongos, o efeito antidepressivo do canabidiol, comparando-o à imipramina. Os resultados mostraram que ambos diminuíram o tempo de imobilidade dos animais, sugerindo também um efeito antidepressivo (Zanelatiet al., 2oro). Todos estes dados demonstram que os canabinóides, sobretudo o canabidiol, podem, no futuro, ser uma importante ferramenta terapêutica no tratamento de sintomas e transtornos psiquiátricos. Contudo, são necessários mais estudos em longo prazo para confirmar estes dados (Crippa; Zuardi; Hallak, 2010).

\section{Canabinóides e epilepsia}

Em 1974, um estudo feito por Perez-Reyes e Wingfield demonstrou que o canabidiol é eficaz nas crises epiléticas que ocorrem durante o sono. Porém, não se sabia bem ao certo sobre a severidade das convulsões nem sua frequência (Perez e Wingfield, 1974). Para elucidar este estudo, 
um médico brasileiro, Dr. Elisaldo Carlini, foi o primeiro a investigar sobre a frequência e as severidades destas crises em pacientes epiléticos, fazendo o uso de canabidióis associados a medicamentos utilizados para as crises epiléticas (Malcher-Lopes, 2014).

O estudo consistia em submeter oito pacientes, todos fazendo uso de algum medicamento para epilepsia, que consumiram de $200-300 \mathrm{mg} / \mathrm{dia}$ de canabidiol puro por via oral durante quatro meses e meio. Os resultados obtidos foram que somente um paciente não obteve melhora, enquanto os outros sete melhoraram, sendo que quatro tiveram convulsões abolidas, e três tiveram suas crises diminuídas. Desta forma, demostrou-se que o canabidiol pode ser um adjuvante no tratamento da epilepsia (Cunha et al., 1980).

A eficácia do canabidiol em bloquear convulsões induzidas por eletrochoque em roedores foi verificada por Kaler e Turkanis, em 1978, comparando a distinção do THC e do canabidiol, uma vez que o THC demonstrou ter efeitos anticonvulsivos em doses baixas e, em doses altas, causar convulsões, diferindo-se do canabidiol que demonstrou somente efeitos anticonvulsivos (Kaler e Turkanis, 1978).

Os testes com canabinóides pararam por conta da guerra contra as drogas, e só retornaram em 2005, quando começaram a testar canabidióis em pacientes infantis com epilepsia e quadros

refratários (Robson, 2005). Neste ano, por exemplo, Pelliccia, Romano e Crocchiolo, submeteram um grupo de crianças à administração oral de canabidiol 2,5\% em óleo de milho. Como resultado, houve uma melhora nos quadros epiléticos e anticonvulsivos das crianças, sem qualquer efeito adverso (Pellicia, Romano e Crocchiolo, 2005).

Em 2013, Porter e Jacobson realizaram uma pesquisa onde submeteram dezenove crianças de 2 a I6 anos à utilização do uso de óleo rico em canabidiol para tratar as convulsões oriundas de doenças como Síndrome de Dravet, Doose, Lenox-Gastaut e epilepsia idiopática. A frequência das convulsões variou entre 2 a 250 por semana de tratamento. $O$ tempo do experimento variou entre duas semanas a um ano. Como resultado, pode-se observar que $84 \%$ das crianças obtiveram melhora no quadro epiléptico com o uso do óleo rico em canabidiol (Malcher-Lopes, 20I4 apoud Porter e Jacobson, 2013).

\section{Canabinóides e Câncer}

Câncer é o nome que se dá a mais de ioo doenças que são caracterizadas pelo crescimento desordenado de células que tendem a invadir tecidos e órgãos adjacentes, tendo estas doenças 
origens genéticas. A oncogênese é constituída de processos que mutam o DNA do hospedeiro, alterando sua função. A identificação de células malignas se dá devido à ausência de respostas a impulsos, sendo que nem todos os tipos de câncer são malignos (Toscano et al., 2008).

Este crescimento incontrolado é denominado neoplasia, que pode ser classificada como benigna ou maligna. A neoplasia benigna é caracterizada pelo crescimento organizado, lento, e de limites nítidos, não invadindo órgãos vizinhos, mas podendo comprimi-los. Já a neoplasia maligna manifesta-se em maior grau e é capaz de invadir tecidos e órgãos adjacentes, provocando metástases. Os pacientes oncológicos apresentam sintomas como dor, fadiga, falta de apetite, náuseas, vômitos, entre outros (INCA 2012).

Os pacientes oncológicos tratados com quimioterápicos tendem a perder peso, bem como sofrer com vômitos e náuseas. Os canabinóides podem ser adjuvantes no tratamento destas doenças. Embora o mecanismo da ação antiemética dos canabinóides ainda não esteja elucidada, buscou-se, em estudos com ratos, verificar seu potencial antiemético. Com base nestes estudos, pode-se concluir que alguns canabinóides podem inibir o vômito através de uma ligação a receptores do trato solitário. Fala-se também da existência de receptores canabinóides no intestino delgado, que poderiam estar sendo alvo de um possível mecanismo antiemético periférico. Ainda podemos citar estudos que mostram que os agonistas canabinóides podem inibir a transmissão serotoninérgica, contribuindo para seus efeitos antieméticos (Duran, 2005).

Recentemente, Tramer et al. revisou as provas clínicas acerca dos canabinóides e sua eficácia antiemética, realizando uma avaliação de 30 estudos clínicos, onde os pacientes que utilizaram algum tipo de composto canabinóide junto com a quimioterapia afirmaram uma melhora em seus sintomas. O que se pôde concluir foi que os canabinóides eram efetivos no tratamento antiemético e por muitos pacientes foi considerado como primeira opção (Tramer et al, 2001).

O dronabinol, um medicamento canabinóide, pode ser utilizado como indutor de apetite, uma vez que este pode alterar a sensação gustativa. Isto se dá devido à presença de endocanabinóides no hipotálamo, regulados pela leptina. Contudo, são necessários mais estudos que confirmem a possibilidade dos canabinóides serem utilizados como indutor do apetite na terapia de pacientes oncológicos (Duran, 2005). A atividade anti-neoplásica dos canabinóides vem sendo estudada desde 1970, porém os estudos deram mais ênfase nos efeitos paliativos dos canabinóides como antieméticos, do que como anti-neoplásicos. No momento atual, busca-se 
saber se as drogas que alvejam o sistema endocanabinoide podem ser utilizadas para retardar ou bloquear o crescimento de tumores (Bifulco; Di Marzo, 2002).

Em testes in vitro, pode-se notar que há receptores canabinóides em células cancerosas, e que os endocanabinóides parecem atuar como inibidores de proliferação de células cancerígenas. Nestes estudos, pode-se perceber que os endocanabinóides também participam na apoptose de células de gliomas e câncer de próstata, embora não se saiba seu mecanismo ao certo. Recentemente, foi relatado que a ativação dos receptores $\mathrm{CB}_{2}$ pode inibir crescimento de gliomas in vivo. Esta descoberta fez com que o governo espanhol permitisse um estudo clinico para investigar esta possibilidade (Bifulco; Di Marzo, 2002).

Em estudo feito com células cancerígenos do pâncreas in vivo e in vitro, pôde-se concluir que os canabinóides tiveram efeitos antitumorais induzindo apoptose das células cancerígenas, sendo, portanto, considerado uma boa aposta no tratamento da doença (Carracedo et al., 2006). Para Massi et al., o canabidiol pode exercer diversas ações benéficas em diferentes tipos de tumores, exercendo ação anti-migratória, anti-invasiva e anti-metastáticas, sendo esta uma hipótese viável para estudos in vitro. Estas ações estariam associadas a uma modulação da sinalização intracelular (Massi et al., 2013).

De acordo com estudos, Salazar et al., concluíram que os canabinóides são agentes antitumorais, pois induzem autofagia, promovendo apoptose. Estes estudos sugerem que esta ação ocorra através da ativação dos receptores $\mathrm{CB}_{\mathrm{I}}$ que estimula a síntese de ceramida e esta, por sua vez, é a responsável por causar estresse à célula, causando a autofagia. Todos estes achados levam a um olhar otimista em relação ao potencial terapêutico dos canabinóides no combater ao câncer (Salazar, et al., 2009).

\section{Fármacos desenvolvidos}

O primeiro medicamento utilizando os canabinóides THC (delta-gtetrahidrocanabinol) e Canabidiol foi o Sativex ${ }^{\circledR}$, submetido a testes clínicos e aprovado para uso sob prescrição médica, no Canadá. Este medicamento tem a apresentação de spray oral, com doses individualizadas, utilizado por pacientes com dores oncológicas, neuropáticas e com esclerose múltipla. A dose usual varia de 8 a 12 doses/dia, consumindo aproximadamente $32 \mathrm{mg} / \mathrm{dia}$ de THC e $30 \mathrm{mg} / \mathrm{dia}$ de canabidiol (Barnes, 2006). 
Atualmente, no mercado há outras opções de medicamentos, como o dronabinol (Marinol ${ }^{\circledR}$ ), um composto sintético do THC, utilizado para redução da pressão intraocular em pacientes com glaucoma (Plange, 2007), e na dosagem diária de 7,5 mg via oral pode ser utilizado também como tratamento auxiliar no aumento de apetite de pacientes com HIV/AIDS, anorexia e câncer terminal (Duran et. al, 2004).

O Cesamet ${ }^{\circledR}$ (nabilona) é um medicamento oriundo de componentes sintéticos de canabinóides. Testes foram feitos com este medicamento a fim de avaliar sua eficácia no tratamento de dores secundárias e ciáticas. Os resultados foram de que doses de 0,25 a $3 \mathrm{mg} / \mathrm{dia}$ produziram os seguintes efeitos nos pacientes: $30 \%$ dos pacientes relataram melhora da qualidade do sono, ansiedade e espasmos musculares; $25 \%$ não toleraram o tratamento, considerando-se como efeitos indesejáveis mais frequentes a disforia e sonolência. O restante dos pacientes submetidos previamente à utilização da Cannabis sativa in natura demonstrou preferência por essa substância em si e não na forma de medicamento (Duran et. al, 2004).

A nabilona é liberada no Canadá na dosagem de Img, podendo ser utilizada até três vezes ao dia; com indicação médica também para dores neuropáticas e como antieméticos. Estes medicamentos são misturas de THC e canabidiol sintético, pois o THC puro pode induzir taquicardia, disforia e sintomas psicóticos (Berlach, 2006).

Com base nos efeitos indutores do apetite dos canabinóides, a empresa Sanofi-Synthelab desenvolveu um medicamento capaz de bloquear os receptores canabinóides e, assim, inibir o apetite, podendo ser útil no tratamento da obesidade. Para isso foi sintetizado o rimonabanto (Accomplia ${ }^{\circledR}$ ), substância sintética que atua como antagonista dos receptores CBı. Contudo, o medicamento foi retirado do mercado rapidamente, pois, apesar de apresentar efeitos na redução de peso, os pacientes que faziam uso deste composto demonstraram disfunções emocionais (Pamplona, 2014 apoud Gadde e Allison, 2006).

$\mathrm{Na}$ Holanda, em 2003, uma variedade híbrida da Cannabis passou a ser vendida em farmácias sob prescrição médica. Esta substância é denominada Bedrocan ${ }^{\circledR}$ e tem sido utilizada como antiemética em pacientes oncológicos e também no alívio de dores neuropáticas de pacientes com HIV/AIDS, tanto na forma de vapor ou em preparações comestíveis (Pamplona, 2014). 


\section{CONCLUSÃO}

Com base nesta revisão, conclui-se que os componentes da Cannabis podem ser utilizados na terapêutica de diversas patologias. Os canabinóides mostraram ser compostos estáveis, ainda que se desconheçam alguns mecanismos de ação em frente a algumas doenças. Porém, trata-se de uma nova alternativa medicamentosa para doenças que até hoje interferem na vida das pessoas. A busca por novas terapias contribui para um melhor bem-estar dos doentes e também faz com que se descubram novos sistemas que funcionam em nosso organismo. A utilização dos canabinóides pode resultar em diversas surpresas, tanto para a área cientifica quanto para os que sofrem de patologias que, por muitas vezes, ficam com sua terapêutica obsoleta.

\section{REFERÊNCIAS}

ANVISA. Importação de medicamentos sem registro no Brasil. vol. 2014.

BARNES, Michael Philip. Sativex ${ }^{\circledR}$ : clinical efficacy and tolerability in the treatment of symptoms of multiple sclerosis and neuropathic pain. 2006.

BERLACH, David M.; SHIR, Yoram; WARE, Mark A. Experience with the synthetic cannabinoid nabilone in chronic noncancer pain. Pain Medicine, v. 7, n. I, p. 25-29, 2006.

BIFULCO, Maurizio; DI MARZO, Vincenzo. Targeting the endocannabinoid system in cancer therapy: a call for further research. Nature medicine, v. 8, n. 6, p. 547-550, 2002.

BITENCOURT, Rafael M.; PAMPLONA, Fabrício A.; TAKAHASHI, Reinaldo N. Facilitation of contextual fear memory extinction and anti-anxiogenic effects of $\mathrm{AM}_{4} \mathrm{O} 4$ and cannabidiol in conditioned rats. European Neuropsychopharmacology, v. I8, n. I2, p. 849-859, 2008.

BONFÁ, Laura; VINAGRE, Ronaldo Contreiras de Oliveira; FIGUEIREDO, Núbia Verçosa de. Uso de canabinóides na dor crônica e em cuidados paliativos. Rev Bras Anestesiol, v. 58, p. 267-279, 2008.

CAMPBELL, Fiona A. et al. Are cannabinoids an effective and safe treatment option in the management of pain? A qualitative systematic review. Bmj, v. 323, n. 7303, p. 13, 2001.

CAMPOS, Alline Cristina; GUIMARAES, Francisco Silveira. Evidence for a potential role for TRPVI receptors in the dorsolateral periaqueductal gray in the attenuation of the anxiolytic effects of cannabinoids. Progress in Neuro-Psychopharmacology and Biological Psychiatry, v. 33, n. 8, p. I517-I52I, 2009. 
CARLINI, Elisaldo A.; CUNHA, Jomar M. Hypnotic and antiepileptic effects of cannabidiol. The Journal of Clinical Pharmacology, v. 21, n. Si, p. 417S-427S, 198I.

CARRACEDO, Arkaitz et al. Cannabinoids Induce Apoptosis of Pancreatic Tumor Cells via Endoplasmic Reticulum Stress-Related Genes. Cancer research, v. 66, n. 13, p. 6748-6755, 2006.

COSTA, A.F. Farmacognosia.3.ed. Lisboa: Editora Coloust Gulbenkian, 1970; r:90-95.

CRIPPA, José Alexandre S.; ZUARDI, Antonio Waldo; HALLAK, Jaime EC. Therapeutical use of the cannabinoids in psychiatry. Revista Brasileira de Psiquiatria, v. 32, p. 556-566, 2010.

DA CRUZ, Paulo Sérgio Aragão; GONÇALVES, Jacqueline Coimbra. O sistema endocanabinoide e o uso da Cannabis sativa no combate as dores crônicas.

CUNHA, Jomar M. et al. Chronic administration of cannabidiol to healthy volunteers and epileptic patients. Pharmacology, v. 21, n. 3, p. 175-185, I980.

DELlAROZA, Mara Solange Gomes; PIMENTA, Cibele Andrucioli; MATSUO, Tiemi. Prevalência e caracterização da dor crônica em idosos não institucionalizados Prevalence and characterization of chronic pain among the elderly living in the community. Cad. saúde pública, v. 23, n. 5, p. II5I-II6o, 2007.

DURAN, Marta; LAPORTE, Joan-Ramon; CAPELLÀ, Dolors. Novedades sobre las potencialidades terapéuticas del Cannabis y el sistema cannabinoide. Medicina clínica, v. I22, n. Io, p. 390-398, 2004.

DURÁN, Marta; CAPELLÀ, D. Uso terapéutico de los cannabinoides. Eguzkilore, v. 19, p. 139I49, 2005 .

FRANCISCHETTI, Emilio Antonio; ABREU, Virginia Genelhu de. O sistema endocanabinóide: nova perspectiva no controle de fatores de risco cardiometabólico. Arq Bras Cardiol, v. 87, p. 548-558, 2006.

HONÓRIO, Káthia Maria; ARROIO, Agnaldo; DA SILVA, Albérico Borges Ferreira. Aspectos terapêuticos de compostos da planta Cannabis sativa.Química nova, v. 29, n. 2, p. 318, 2006.

INCA. ABC do câncer: abordagens básicas para o controle do câncer / Instituto Nacional de Câncer José Alencar Gomes da Silva, Coordenação Geral de Ações Estratégicas, Coordenação de Educação; organização Luiz Claudio Santos Thuler. - 2. ed. rev. e atual.- Rio de Janeiro : Inca, 2012.

KALANT, Harold. Medicinal use of cannabis: history and current status. Pain Research and Management, v. 6, n. 2, p. 80-94, 200I. 
KARLER, R.; TURKANIS, S. A. Cannabis and epilepsy. Advances in the biosciences, v. 22, p. 6I9-64I, I977.

KARNIOL, I. G.; CARLINI, E. A. Pharmacological interaction between cannabidiol and $\delta_{9-}$ tetrahydrocannabinol. Psychopharmacologia, v. 33, n. I, p. 53-70, 1973.

LEWEKE, F. Markus et al. Different effects of nabilone and cannabidiol on binocular depth inversion in man. Pharmacology Biochemistry and Behavior, v. 66, n. I, p. 175-181, 2000.

MATSUDA, Lisa A. et al. Structure of a cannabinoid receptor and functional expression of the cloned cDNA. Nature, v. 346, n. 6284, p. 56r-564, 1990.

MALCHER-LOPES, Renato. Canabinóides ajudam a desvendar aspectos etiológicos em comum e trazem esperança para o tratamento de autismo e epilepsia. Revista da Biologia, v. 13, n. I, p. 4359, 2014 .

MALCHER-LOPES, Renato; RIBEIRO, Sidarta. Maconha, cérebro e saúde. Vieira \& Lent, 2007.

MASSI, Paola et al. Cannabidiol as potential anticancer drug. British journal of clinical pharmacology, v. 75, n. 2, p. 303-312, 2013.

MOREIRA, Fabrício A.; GUIMARÃES, Francisco S. Cannabidiol inhibits the hyperlocomotion induced by psychotomimetic drugs in mice. European journal of pharmacology, v. 512, n. 2, p. 199-205, 2005.

MUSTY, R. E.; CONTI, L. H.; MECHOULAM, R. Anxiolytic properties of cannabidiol. In: Marihuana'84: proceedings of the Oxford Symposium on Cannabis: 9th International Congress of Pharmacology, 3rd Satellite Symposium on Cannabis/edited by DJ Harvey; assistant editors Sir William Paton, GG Nahas. Oxford: IRL Press, cr985., 1985.

NAIMARK, David et al. Psychotic symptoms in Parkinson's disease patients with dementia. Journal of the American Geriatrics Society, v. 44, n. 3, p. 296-299, 1996.

ONAIVI, Emmanuel S.; GREEN, MAUDE R.; MARTIN, Billy R. Pharmacological characterization of cannabinoids in the elevated plus maze.Journal of Pharmacology and Experimental Therapeutics, v. 253, n. 3, p. 1002-1009, 1990.

PAMPLONA, Fabricio A. Quais são e pra que servem os medicamentos à base de Cannabis?. Revista da Biologia, v. I3, n. I, p. 28-35, 2014.

PELLICIA, A. et al. Treatment with CBD in oily solution of drug-resistant paediatric epilepsies. In: Congress on Cannabis and the Cannabinoids, Leiden, The Netherlands: International Association for Cannabis as Medicine. 2005. p. I4. 
PEREZ-REYES, Mario; WINGFIELD, Martha. Cannabidiol and electroencephalographic epileptic activity. JAMA, v. 230, n. 12, p. 1635-1635, 1974.

PETROCELLIS, Luciano De; CASCIO, Maria Grazia; MARZO, Vincenzo Di. The endocannabinoid system: a general view and latest additions. British journal of pharmacology, v. I4I, n. 5, p. 765-774, 2004.

PLANGE, Niklas et al. Dronabinol and retinal hemodynamics in humans. American journal of ophthalmology, v. I43, n. I, p. 173-174, 2007.

RESSTEL, Leonardo BM et al. Effects of cannabidiol and diazepam on behavioral and cardiovascular responses induced by contextual conditioned fear in rats. Behavioural brain research, v. 172, n. 2, p. 294-298, 2006.

RESSTEL, Leonardo et al. 5-HTIA receptors are involved in the cannabidiol-induced attenuation of behavioural and cardiovascular responses to acute restraint stress in rats. British journal of pharmacology, v. 156, n. I, p. I8I-188, 2009.

ROBSON, Philip. Human studies of cannabinoids and medicinal cannabis. In:Cannabinoids. Springer Berlin Heidelberg, 2005. p. 719-756.

SALAZAR, María et al. Cannabinoid action induces autophagy-mediated cell death through stimulation of ER stress in human glioma cells. The Journal of clinical investigation, v. II9, n. 5 , p. 1359, 2009.

SILVEIRA FILHO, Nylson G.; TUFIK, Sérgio. Comparative effects between cannabidiol and diazepam on neophobia, food intake and conflict behavior.Research Communications in Psychology, Psychiatry \& Behavior, 198I.

THANVI, B. R.; LO, T.; HARSH, D. P. Psychosis in Parkinson's disease. Postgraduate medical journal, v. 8I, n. 960, p. 644-646, 2005.

ZANELATI, T. V. et al. Antidepressant-like effects of cannabidiol in mice: possible involvement of 5-HTIA receptors. British journal of pharmacology, v. 159, n. I, p. I22-128, 2010.

ZUARDI, A. W. et al. Cannabidiol for the treatment of psychosis in Parkinson's disease. Journal of Psychopharmacology, 2008.

ZUARDI, A. W.; RODRIGUES, J. Antunes; CUNHA, J. M. Effects of cannabidiol in animal models predictive of antipsychotic activity.Psychopharmacology, v. I04, n. 2, p. 260-264, I991.

ZUARDI, A. W. et al. Cannabidiol, a Cannabis sativa constituent, as an antipsychotic drug. Brazilian journal of medical and biological research, v. 39, n. 4, p. 421-429, 2006.(B) 
ZUARDI, Antonio Waldo. História da Cannabis como medicamento: uma revisão. Revista Brasileira de Psiquiatria, v. 28, n. 2, p. 153-157, 2006. (A)

ZUARDI, A. W.; KARNIOL, I. G. Changes in the conditioned emotional response of rats, induced by delta-9-thc, cbd and mixture of the 2 cannabinoids. Arquivos de Biologia e Tecnologia, v. 26, n. 3, p. 391-397, 1983. 